\title{
UMA RELEITURA DA USUCAPIÃO POR ABANDONO DE LAR SOB A ÓTICA DO DIREITO CIVIL BRASILEIRO
}

\author{
Claudilene dos Santos Ramalho \\ Acadêmica do 9o Período do Curso de Direito da Universidade Presidente Antônio \\ Carlos - UNIPAC Teófilo Otoni - MG - Brasil \\ E-mail: kalenasr@hotmail.com \\ Fernanda da Silva Freitas \\ Advogada e Professora de Direito na Faculdade Presidente Antônio Carlos de \\ Teófilo Otoni. Especialista em Direito Público e em Docência no Ensino Superior \\ E -mail: ferna-freitas@hotmail.com
}

Recebido: 01/05/2020 - Aceito: 20/05/2020

\section{RESUMO}

Em 17 de junho de 2011, a legislação civil foi alterada, apresentando nova modalidade de usucapião, desta feita decorrente do abandono do lar. Este artigo visa analisar de forma crítica a nova usucapião e os seus reflexos na área do Direito da Família. Com efeito, pensamos que ao evocar culpa pelo fim do relacionamento, revigorando como causa o abandono de lar, o dispositivo se mostra anacrônico e na contramarcha da evolução do direito contemporâneo, na qual cada vez mais se afasta qualquer discussão judicial acerca de quem deu causa ao rompimento do vínculo, deixando tal questão para a esfera íntima dos indivíduos. Dúvidas surgem a respeito da aplicação da lei, especialmente da interpretação do abandono de lar. Esse conceito foi resgatado pelo legislador apesar do avanço da lei brasileira que permite o divórcio direto, além de construção jurisprudencial que afasta a culpabilidade no reconhecimento do direito ao rompimento dos vínculos entre casais. Propõe-se a interpretação da nova lei com o intuito de proteger o direito de moradia, compreendendo o abandono de lar como atitude de desamparo da família, para conferir proteção àquele que se encontra em situação de vulnerabilidade permitindo a regularização do imóvel com agilidade. A ação deve ser processada e julgada em Vara de Família, por se tratar de questão decorrente de direitos e deveres entre excasais.

Palavras-chave: Usucapião familiar; abandono de lar; direitos fundamentais.

\section{ABSTRACT}

On June 17, 2011, civil legislation was changed, introducing a new form of adverse possession, this time due to the abandonment of the home. This article aims to critically analyze the new adverse possession and its reflexes in the area of Family Law. In fact, we think that by evoking guilt over the end of the relationship, reinvigorating the abandonment of the home as a cause, the device proves to be 
anachronistic and in opposition to the evolution of contemporary law, in which any judicial discussion about who gave cause to the breaking of the bond, leaving this question to the intimate sphere of individuals. Doubts arise regarding the application of the law, especially the interpretation of abandonment of the home. This concept was rescued by the legislator despite the advancement of Brazilian law that allows direct divorce, in addition to jurisprudential construction that removes the guilt in recognizing the right to break bonds between couples. It is proposed to interpret the new law in order to protect the right to housing, including abandoning the home as an attitude of helplessness of the family, to provide protection to those who are in a situation of vulnerability, allowing the regularization of the property with agility. The lawsuit must be processed and judged by the Family Court, as it is an issue arising from rights and duties between ex-couples.

Keywords: Family adverse possession; abandonment of home; fundamental rights.

\section{INTRODUÇÃO}

O presente artigo científico tem por finalidade apresentar, a usucapião por abandono de lar, também conhecida pelos doutrinadores como usucapião familiar.

O método que será utilizado na produção do trabalho está amparado em pesquisas bibliográficas e doutrinárias, bem como nas legislações e jurisprudências pertinentes ao tema.

A pesquisa busca investigar os requisitos da usucapião por abandono do lar, com objetivo de saber como é feita a proteção do lar na atual conjuntura mundial.

A problematização a que nos referiremos no presente trabalho baseia-se não apenas no renascimento da figura do abandono do lar e o que ela sempre representou no caminho percorrido dentro do Direito de Família no Brasil ao consolidar o patenteamento de um paradigma familiar uniforme e, por certo aspecto, bastante excludente, mas, sobretudo, quais seriam suas reais motivações e interpretações, posto que há uma nebulosidade normativa no texto da lei.

O instituto também deve ser analisado em consonância com a função social da propriedade, princípio jurídico que orienta e exige o aproveitamento desta no intuito de assegurar o bem-estar da sociedade como um todo, condenando o proprietário pela má utilização ou até mesmo pelo desuso de determinado bem.

A relação direta com o Direito de Família torna ainda mais significativa a discussão sobre o tema. Com intenção de esclarecer o vocábulo "abandono de lar" utilizado pela Lei $\mathrm{n}^{\circ} \mathbf{1 2 . 4 2 4 / 2 0 1 1}$, é relevante para a sociedade analisar o objetivo da 
norma ao se referir ao abandono, pois muitas são as críticas ao que poderia caracterizá-lo.

\section{SURGIMENTO DA USUCAPIÃO POR ABANDONO DE LAR}

O instituto da usucapião foi positivado pela primeira vez na famosa Lei das XII Tábuas, pela qual a aquisição da propriedade se daria no prazo de um ano para os bens móveis e de dois anos para os bens imóveis. Para que restasse configurada a usucapião, dever-se-ia satisfazer determinadas condições como coisa idônea, posse continuada por certo período de tempo, justo título ou justa causa e boa-fé. Salientou ROSENVALD:

A usucapião restou consagrada na lei das Doze Tábuas, datada de 455 antes de Cristo, como forma de aquisição de coisas móveis e imóveis pela posse continuada por um ou dois anos. Só poderia ser utilizada pelo cidadão romano, eis que os estrangeiros não gozavam de direitos preceituados no iuscivile. Desta forma, os romanos mantinham os seus bens perante os peregrinos e podiam reivindicá-los quando bem entendessem. Sendo a transmissão da propriedade romana cercada de diversas solenidades, no início a ação de usucapião era utilizada para convalidar aquisições formalmente nulas ou aquelas ineficazes por vício ou defeito de legitimação, quando presente a boa fé do possuidor. (ROSENVALD, 2011, p. 272)

Posteriormente, no Direito Clássico, surgiu também a chamada "praescriptio", que figurava como uma modalidade de exceção e meio de defesa. Conforme ensina Venosa, "quem possuísse um terreno provincial por determinado lapso temporal poderia repelir qualquer ameaça à sua propriedade através do longo tempo praescriptio". 1

É de se ressaltar que a usucapio, como modalidade de aquisição do ius civile, era apenas destinada aos cidadãos romanos, ao passo que a prescrição ao longo tempo podia ser utilizada tanto pelos romanos quanto pelos estrangeiros.

Com o passar do tempo, sucessivas leis foram restringindo o campo de aplicação da usucapião. Esclarece MONTEIRO que:

\footnotetext{
A Lei Atínea proibiu a usucapião de coisas furtivas, tanto para o ladrão quanto para o receptor; as Leis Júlia e Pláucia ampliaram a proibição às coisas obtidas mediante violência; e a Lei Scribonia vedou a usucapião das servidões prediais. (MONTEIRO, 2010, p.120.)
}

\footnotetext{
1 VENOSA, Sílvio de Salvo. Direito Civil: direitos reais. 12. ed. São Paulo: Atlas, 2012. p. 200.
} 
Foi, porém, no Direito de Justiniano, no século VI, que a usucapião apareceu como um instituto consolidado e aperfeiçoado, porquanto foi reformulado de maneira quase total. O imperador unificou os dois institutos: a usucapião das XII Tábuas (usucapio) e a prescrição a longo tempo (longi temporis praescriptio), daí resultando a denominada "usucapião". 2

A usucapião nasce, portanto, da fusão entre dois institutos de mesma natureza, porém com campos de atuação diversos ${ }^{3}$.

Atualmente, a usucapião não só figura no Código Civil e em outras leis extravagantes, como no Estatuto da Cidade; regulamentado pela Lei oㅡ 10.257/01 e artigos 182 e 183, da Constituição Federal, possuindo status de ordem constitucional. Senão, vejamos:

Art.182. A política de desenvolvimento urbano, executada pelo poder público municipal, conforme diretrizes gerais fixadas em lei, tem por objetivo ordenar o pleno desenvolvimento das funções sociais da cidade e garantir o bem-estar de seus habitantes. Art.183. Aquele que possuir como sua área urbana de até duzentos e cinqüenta metros quadrados, por cinco anos, ininterruptamente e sem oposição, utilizando-a para sua moradia ou de sua família, adquirir-Ihe-á o domínio, desde que não seja proprietário de outro imóvel urbano ou rural. (CONSTITUIÇÃO FEDERAL,1988).

Diante do contexto histórico apresentado, nota-se que o Direito Brasileiro foi fortemente influenciado pelo Direito Romano, principalmente no que toca aos requisitos para a configuração da usucapião.

\section{EM QUE CONSISTE A USUCAPIÃO}

A usucapião é, indiscutivelmente, um modo particular de aquisição da propriedade. Com efeito, ela insere no patrimônio do usucapiente direitos que antes não existiam.

Conforme o doutrinador ORLANDO GOMES:

2 CORDEIRO, Carlos José. Usucapião Constitucional Urbano: Aspectos de direito material. São Paulo: Max Limonad, 2001. p. 87.

${ }^{3}$ Sobre este aspecto, Silvio de Salvo Venosa ressalta: "Daí a razão de, com frequência, utilizar-se a expressão prescrição aquisitiva como sinônimo de usucapião. De fato, enquanto a prescrição extintiva, ou prescrição propriamente dita, implica perda do direito, o usucapião permite a aquisição do direito de propriedade. Em ambas as situações, levam-se em consideração o decurso de certo tempo". (VENOSA, Sílvio de Salvo. Direito Civil: direitos reais. 12. ed. São Paulo: Atlas, 2012. p. 200). 


\title{
Revista Jurídica do Nordeste Mineiro, v 01, 2020/01
}

Dentre os diversos conceitos apresentados pela doutrina, o que mais se relaciona com o ordenamento jurídico brasileiro é o conceito clássico de Modestino, segundo o qual, a usucapião é um dos modos de aquisição da propriedade e de outros direitos reais", isto é, a usucapião é o modo de adquirir a propriedade pela posse continuada durante certo lapso de tempo, com os requisitos estabelecidos na lei.(GOMES, 1996, p.163)

No entanto, conforme alerta (MONTEIRO, 2010), é necessário lembrar que a usucapião, além de ser forma de adquirir o domínio, também é modo de aquisição de outros direitos reais, tais quais o usufruto, o uso, as servidões, a habitação, dentre outros.

Diverge a doutrina sobre ser ou não a usucapião uma forma de prescrição. Para alguns autores, ao lado da prescrição extintiva estaria a usucapião, denominada por eles de prescrição aquisitiva, de modo que os dois institutos seriam espécies do mesmo gênero.

A respeito de tal discussão, (GOMES, 1996), embora tenha reconhecido pontos de semelhança entre os dois institutos, como o decurso de tempo, a inércia do titular do direito e a finalidade de eliminação das incertezas do direito, rechaçou fortemente a ideia de prescrição aquisitiva como sinônimo de usucapião, tendo em vista as profundas diferenças que os afastariam. Nos dizeres do ilustre doutrinador:

\begin{abstract}
A prescrição é um modo de extinguir pretensões. A usucapião um modo de adquirir a propriedade e outros direitos reais, conquanto acarrete, por via de consequência, a extinção do direito para o antigo titular. A prescrição opera com base na inércia do sujeito de direito durante certo lapso de tempo. A usucapião supõe a posse continuada. A prescrição extingue as pretensões reais e pessoais, tendo largo campo de aplicação, enquanto a usucapião restringe-se aos direitos reais, dos quais é modo de aquisição. Os direitos pessoais não se adquirem por usucapião. (GOMES, 1996, p.161)
\end{abstract}

Neste mesmo sentido, ensina que, na usucapião, predomina a força geradora, sendo que a extinção do direito vem por via de consequência, pois o proprietário perde o domínio porque o adquire o possuidor. Refere que a lei toma a usucapião pelo seu lado positivo, considerando-a modo de aquisição de direitos, e assim a regula definindo as suas condições e efeitos. Por outro lado, a prescrição, conforme esclarece o jurista, é negativa, uma vez que nasce da inércia e tem por efeito a dissolução da obrigação, paralisando o direito correlato e, consequentemente, não gerando direitos. ${ }^{4}$

\footnotetext{
${ }^{4}$ PEREIRA, Lafayette Rodrigues. Direito das coisas. 6. ed. São Paulo: Freitas Bastos, 1956. p. 165-
} 166. 
Seguindo esta linha de raciocínio, assinala, então, que a usucapião tem sido denominada impropriamente prescrição aquisitiva. ${ }^{5}$

No entanto, fato é que, apesar das diferenças e semelhanças apresentadas, o uso da expressão prescrição aquisitiva como sinônimo de usucapião já é corrente majoritária na doutrina e na jurisprudência, de modo que cabe ao intérprete, ao utilizar as palavras de forma indistintas, afastar o sentido estrito da palavra prescrição, conforme orienta SALLES:

Basta que se ressalte, portanto, que a prescrição propriamente dita ou
prescrição extintiva vem regulada na Parte Geral do atual Código Civil
Brasileiro, Livro III, Título IV, ao passo que a prescrição aquisitiva ou
usucapião, está disciplinada na Parte Especial, Livro III (Do Direito das
Coisas), Título III, arts. 1.238 a 1.244 e arts. 1,260 a 1.262. (SALLES, 2010,
p.191)

Outrossim, há divergência doutrinária quanto à usucapião ser modo originário ou derivado de aquisição da propriedade.

O renomado PEREIRA, (2012), adotando uma posição minoritária, inclui a usucapião no rol dos modos derivados de aquisição de propriedade, sob o argumento de que o instituto pressupõe a perda do domínio por outrem, em benefício do usucapiente.

Dessa forma, em virtude da aquisição por usucapião estar relacionada com outro indivíduo que já era proprietário do mesmo bem e que o perdeu em favor do adquirente, defende o jurista que a usucapião deve ser considerada uma forma de aquisição derivada, embora reconheça que Ihe falte a circunstância da transmissão voluntária ${ }^{6}$.

Ocorre, todavia, que a maior parte da doutrina e, inclusive, a jurisprudência, classifica a usucapião como modo originário, por não se tratar de forma de aquisição que derive de ato negocial realizado entre o usucapiente e o antigo titular.

Nesse sentido, destaca-se a lição de SALLES:

Ora, comprovada, pelo usucapiente, a posse mansa e pacífica pelo tempo fixado em lei, adquire ele a propriedade do bem pelo só fato do preenchimento dos requisitos previstos na legislação atinente à espécie, sem se indagar de transmissão pelo titular anterior, que perdeu a propriedade. Em outras palavras, desaparece uma propriedade e surge

\footnotetext{
5 PEREIRA, Caio Mário da Silva. Instituições de Direito Civil, Vol. IV. 15. ed. Rio de Janeiro: Forense, 2001. p. 96.

${ }^{6}$ PEREIRA Caio Mário da Silva. op.cit, p. 68.
} 


\title{
Revista Jurídica do Nordeste Mineiro, v 01, 2020/01
}

outra; todavia não se pode afirmar que tenha havido transmissão. Verificouse modo originário de aquisição da propriedade. (SALLES, 2010, p. 50-51)

Feito um breve estudo no que diz respeito aos aspectos fundamentais da usucapião, precípuo, pois, que se conheça o desenvolvimento histórico do instituto da usucapião por abandono de lar.

\section{DO ABANDONO DO LAR NO DIREITO CIVIL BRASILEIRO}

O abandono do lar sempre foi visto sob a ótica do dever de coabitação. Vale dizer, para que o dever de coabitação fosse preservado, o cônjuge deveria estar presente no lar conjugal. A ausência de um dos consortes sem uma justificativa plausível representava o desrespeito ao dever de coabitação, contudo, só isto ainda não significava necessariamente a presença de abandono.

A Lei 12.424/2011 inseriu no Código Civil de 2002, o artigo 1.240-A, que prevê a modalidade de usucapião familiar por abandono de lar, ao dizer que:

\begin{abstract}
ART.1.240-A aquele que exercer, por 2 (dois) anos, ininterruptamente e sem oposição, posse direta, com exclusividade, sobre o imóvel urbano de até $250 \mathrm{~m}^{2}$ (duzentos e cinquenta metros quadrados) cuja propriedade divida com ex-cônjuge ou ex-companheiro que abandonou o lar, utilizando-o para sua moradia ou de sua família, adquirir-lhe-á o domínio integral, desde que não seja proprietário de outro imóvel urbano ou rural. § 10 0 direito previsto no caput não será reconhecido ao mesmo possuidor mais de uma vez. (CÓDIGO CIVIL, 2002).
\end{abstract}

Com isso criou o instituto da usucapião familiar, exigindo, como um de seus requisitos, o abandono do lar pelo cônjuge meeiro. Tal requisito - abandono do lar passou a propiciar grande celeuma. O requisito, sem dúvida, mais polêmico trazido pelo novo dispositivo legal é justamente a exigência do abandono do lar. Isto porque está vinculado ao dever de coabitação e, como comentado anteriormente neste trabalho, à existência de um rol de deveres do matrimônio vem sendo um desafio hermenêutico da doutrina que tentava coadunar o dever legalmente imposto de coabitação entre os cônjuges com os ditames constitucionais, entre eles o da dignidade da pessoa humana e da liberdade.

A inserção do referido requisito em instituto criado após a Emenda Constitucional 66/2010 se apresentou como um retrocesso por permitir ressuscitar a figura de um dever que, aparentemente, em sua interpretação histórica, afronta aos 
ditames constitucionais. Igual retrocesso se configura na possibilidade de ressuscitar a culpa pela ruptura do matrimônio, o que afronta o princípio da dignidade em todos os seus aspectos, entre eles o da intimidade ${ }^{7}$.

A preocupação ganhou relevância, tendo sido aprovado o Enunciado 499 da V Jornada de Direito Civil sugerindo uma apreciação cautelosa do abandono do lar para aplicação do instituto da usucapião familiar, orientando que este deveria ser analisado concomitantemente com a ruptura de outros ditames legais, como o dever de assistência material.

\begin{abstract}
A aquisição da propriedade na modalidade de usucapião prevista no art. 1.240-A do Código Civil só pode ocorrer em virtude de implemento de seus pressupostos anteriormente ao divórcio. O requisito "abandono do lar" deve ser interpretado de maneira cautelosa, mediante a verificação de que o afastamento do lar conjugal representa descumprimento simultâneo de outros deveres conjugais, tais como assistência material e sustendo do lar, onerando desigualmente aquele que se manteve na residência familiar e que ser responsabiliza unilateralmente pelas despesas oriundas da manutenção da família e do próprio imóvel, o que justifica a perda da propriedade e a alteração do regime de bens quanto ao imóvel objeto de usucapião. (Enunciado 499 da V Jornada de Direito Civil da Justiça Federal) ${ }^{8}$
\end{abstract}

Ressalta FARIAS, (2015) que não se poderá reconhecer a usucapião quando a saída do lar conjugal tiver sido autorizada judicialmente em sede de ação de separação de corpos, devendo ser qualificadas por condutas (comissivas ou omissivas) que explicitem uma ruptura da vida conjugal.

Contudo, é de ressaltar que também no vetusto regime, o abandono do lar não se configurava quando o cônjuge obtinha uma autorização judicial para a sua saída do lar conjugal. Antes do advento da Constituição Federal de 1988, a concessão de tais autorizações decorria de comprovação, pelo cônjuge cuja saída era pleiteada, de alguma conduta infratora dos deveres do matrimônio pelo outro cônjuge, o que tornava a vida conjugal insuportável. Com a promulgação da Constituição Federal de 1988 a autorização para a saída do lar passou a ser mais flexível por força da aplicação do princípio da dignidade da pessoa humana nas relações de família, como acima mencionado, mas não prescindia da exposição fática sobre os motivos da decisão de ruptura com o dever de coabitação.

\footnotetext{
7 FREITAS, Douglas Phillips. A usucapião e Direito de Família: Comentários ao Artigo 1.240- A do Código Civil. Revista Síntese Direito de Família. v.14, n.71, p.9-15, abr./maio,2012. p.10.

8 http://www.cjf.jus.br/enunciados/enunciado/499.
} 
Com o advento da Lei 12.424/2011, retorna-se, por consequência óbvia, à análise da saída justificada ou não do cônjuge do lar conjugal, o que implica em exposição de fatos afetos à intimidade das pessoas envolvidas. Repristina-se mesmo que pela via indireta, a análise da justa-causa do abandono do lar (leia-se, quebra do dever de coabitação) e culpa, elementos associados por sua própria essência ontológica.

Tenta-se argumentar que o requisito "abandono do lar" estaria dissociado desta noção culposa, devendo ser interpretado, apenas, como uma separação de fato. Contudo, mais uma vez, a solução não se desvirtua da possibilidade de o cônjuge que se retirou provar a justa causa em fazê-lo, imputando ao cônjuge que permaneceu no imóvel condutas que tornaram insuportável a vida em comum, assim como a infração a algum dos "deveres" do casamento. A culpa, pois, volta a assombrar a vida dos cônjuges, afrontando-se o direito à intimidade e da dignidade da pessoa humana.

\section{DOS REQUISITOS PARA A USUCAPIÃO POR ABANDONO DO LAR}

Pois bem, são requisitos exigidos para a configuração da usucapião familiar: 0 lapso temporal de 2 anos ininterruptos de posse direta de um dos cônjuges/ companheiros; a característica específica do imóvel, que deve ser de até $250 \mathrm{~m}^{2}$, não podendo o cônjuge que pleiteia a usucapião ser proprietário (a) de qualquer outro imóvel seja ele urbano ou rural; e a propriedade do imóvel dever ter sido compartilhada com o ex-cônjuge/companheiro.

No entanto, quando se pensa na expressão abandono de lar é difícil precisar ao certo quando pode vir a se configurar.

Nesse sentido, BANHARA:

O ponto mais polêmico do dispositivo, no entanto, e que pode gerar dúvidas diz respeito à expressão "abandono de lar". Por abandono de lar entende-se a conduta de sair, a deserção do lar conjugal, a cessação do amparo voluntário. Dessa forma é relevante que se perceba que para se configurar o abandono de lar é necessário que se avalie um elemento subjetivo, relativo à intenção daquele que abandonou o lar, no sentido de deserção familiar, de dolosamente evadir-se deixando a família ao desamparo. A saída de um dos cônjuges ou conviventes por motivos alheios à sua vontade não pode ser caracterizada como abandono de lar, assim entendase que a internação, a mudança de cidade por motivos profissionais, por exemplo, não pode ser meramente taxada de abandono de lar. (BANHARA, 2012, p.68). 
Apesar de não parecer ter divergências a princípio por conta da literalidade do artigo, o instituto vem sendo estudado por alguns doutrinadores que após analisarem em segundo plano perceberam que assim como soluções, a usucapião por abandono de lar traz consigo também muita diversidade.

O maior problema decorrente da presença do requisito abandono do lar é que ele evoca a questão da discussão da culpa pelo término da relação conjugal. Ao estatuir como dever conjugal a coabitação, o abandono do lar configurava-se uma infração e causa de imputação de culpa.

A exigência traz verdadeiro renascimento da perquirição da culpa pela extinção da sociedade marital, uma questão que vem sendo cada vez mais afastada e superada pela doutrina e jurisprudência civilista brasileiras.

Com efeito, necessário fazer brevíssima digressão sobre a evolução do Direito da Família no que tange à imputação de culpa pelo término do casamento, para possibilitar uma melhor análise da questão posta.

Embora ainda presente no ordenamento civil, a perquirição da culpa pelo término do casamento, há muito vem sendo mitigada.

Desde então, começou a tomar corpo no universo jurídico nacional a importância de uma fronteira a ser observada e que diz respeito ao limite da intervenção do Estado nas relações familiares, porque as normas para reger essas organizações e as decorrências de seu desfazimento devem ser limitadas ao essencial para que não interfiram na liberdade ou na inviolabilidade da privacidade do sujeito.

Para a grande maioria da doutrina nacional e operadores do direito, a discussão da culpa está praticamente superada, até porque além de inócua mostrase prejudicial aos sujeitos que já sofrem pelo término da relação conjugal.

A própria democratização das relações familiares e a isonomia dos cônjuges na administração da família a transformou em célula do companheirismo. De um lado, a isonomia acentuou a desnecessidade de ingerência do Estado na vida interna da família, mas, por outro, abre para o casal os mais ousados desafios para o exercício cooperativo da conjugalidade e, acaso o par não consiga interna corporis superar as adversidades, o assunto deverá permanecer reservado ao âmbito privado do casal. 


\section{Revista Jurídica do Nordeste Mineiro, v 01, 2020/01}

Por certo que o Estado deve participar da família, especialmente para garantir a observância dos princípios constitucionais, como o da igualdade. Mas, não podemos olvidar que essa ingerência é limitada na pessoa, na sua intimidade e autonomia de vontade.

A questão da averiguação da culpa mostra-se de todo inconveniente. De fato, a necessidade de se perquirir quem foi o culpado pela separação é ultrapassada e até mesmo prejudicial aos sujeitos.

Diante disso a ideia predominante é que a inquirição da culpa pelo rompimento das relações familiares de conjugalidade deveria ser banida de nosso ordenamento jurídico, uma vez que contraria os anseios da sociedade contemporânea.

Do mesmo modo, quando se analisa a ruptura de um vínculo, pelo próprio fato de estarmos diante de uma relação íntima entre duas pessoas, torna-se difícil averiguar a presença de um único culpado e, se aceitarmos o afeto como núcleo e suporte do relacionamento familiar, consequentemente, temos de aceitar a corresponsabilidade dos que nutrem o respectivo vínculo.

Com isso, exatamente dando relevo à preservação da intimidade do sujeito, é que a perquirição da culpa foi cada vez mais afastada, culminando com a promulgação da Emenda Constitucional n 66/2010, que trata do divórcio e que elimina, de uma vez por todas, a discussão da culpa, pois o que é considerado para a ruptura da relação conjugal não é quem foi o culpado, mas o fim do amor e da vontade de permanecer juntos.

A tendência do ordenamento jurídico é cada vez mais possibilitar a decretação da separação, agora do divórcio, pelo simples desamor e sem imputação da causa do término a qualquer das partes e, assim, a discussão da culpa fica afastada, mesmo porque todos os reflexos jurídicos dessa condenação tendem a desaparecer totalmente, tornando-se inócuo apontar o culpado.

Com efeito, a ausência de perquirição da culpa vai ao encontro da tendência evolutiva dos ordenamentos jurídicos ocidentais, onde o Estado interfere cada vez menos na vida privada e na intimidade dos cidadãos.

Assim, a nova lei que insere o art. 1.240-A no Código Civil retroage, pois com ela se volta à análise da discussão da culpa, já que a regra põe em relevo a presença, ou não, do abandono do lar. 
Em vista do novo dispositivo, traz-se a visão de FIGUEIREDO, (2011), quando alerta:

\begin{abstract}
O mais difícil será visualizar uma realidade de embate entre cônjuges para provar quem foi o real culpado a fim de que um deles se torne proprietário do bem do casal. Creio que uma lei não pode estimular a desagregação familiar. (FIGUEIREDO,2011, 123/124.)
\end{abstract}

Como bem ressaltou a festejada DIAS, (2011), "a lei ressuscita a identificação da causa do fim do casamento, que em boa hora foi sepultada pela EC no 66/2010 que, ao acabar com a separação, fez desaparecer prazos e atribuição de culpas”.

Enfim, a regra legal ora estudada acaba por fazer renascer uma discussão que já estava praticamente banida do sistema e, neste aspecto, representa verdadeiro retrocesso legislativo, até porque pune patrimonialmente 0 cônjuge/companheiro que se afastou do lar, muitas vezes por necessidade quiçá até de preservação (sua ou da família); e, por outro lado, premia o cônjuge/companheiro que, em tese, teria sido injustamente abandonado, com a aquisição da propriedade da metade do imóvel residencial que pertence ao outro.

Reinserir a discussão da culpa no sistema, dando relevo ao abandono do lar conjugal, sobretudo punindo aquele que sai e premiando o cônjuge que fica, pode redundar em grave injustiça, e reforça a arraigada ideia de que aquele que sai, perde todos os seus direitos.

Cumpre destacar que são justamente as pessoas menos privilegiadas e que detém menos informações as que acreditam que sair de casa as faz perder tudo e, por vezes, mesmo sofrendo violência física resistem a deixar o lar para não serem prejudicados em seus direitos e se obrigam, mesmo correndo riscos, a permanecerem na moradia. Acaba sendo um obstáculo, a figura do "abandono de lar" em situação de violência.

\title{
6 CONSIDERAÇÕES FINAIS
}

A análise dos direitos assegurados à família pela legislação brasileira representa sério compromisso da sociedade, sobretudo, em razão do crescimento das demandas judiciais pleiteando garantias inerentes ao Direito de Família. A nova realidade demonstra um desafio para a sociedade brasileira, a qual precisa ater-se à 


\section{Revista Jurídica do Nordeste Mineiro, v 01, 2020/01}

busca de condições que resultem na concretização de tais direitos e princípios que conduzem o Direito de Família.

Faz-se necessário o empenho de todos os seguimentos sociais em atenção a essa instituição basilar da sociedade, com atenção à dimensão social das políticas públicas, dando prioridade absoluta no trato com tais demandas, protegendo-as da violência do abandono familiar e também estatal, de forma a garantir sua dignidade.

A lei 12.424/2011, pertencente ao Direito Real, que inovou ao trazer a usucapião familiar está vinculada à dissolução dos vínculos afetivos, e por isso está diretamente ligada ao Direito de Família. Traz uma situação totalmente nova, uma vez que as ações de divórcio e de dissolução da União estável podem ser cumuladas com o pedido de usucapião sobre o imóvel do casal, independente do regime de partilha dos bens por eles eleito. Nesse contexto deve-se invocar os princípios do Direito de Família, como demonstrado e também a Constituição Federal, uma vez que esse diploma tem permeado cada vez mais as relações familiares.

É esta lei, uma política pública de cunho social que visa a proteção daqueles que mais precisam num momento difícil como o de abandono, e deve ser aceita como tal. Esta, sob a proteção da Constituição Federal, tem como escopo a dignidade da pessoa humana da qual nascem todos os outros direitos. A família deixou de ter apenas uma função produtiva e reprodutiva e passou a ser uma entidade de afeto e de solidariedade, pautada em relações pessoais, cujo principal foco é o desenvolvimento da pessoa humana.

Assim, os princípios de Direito de Família aqui estudados - dignidade da pessoa humana, igualdade jurídica dos cônjuges e companheiros, não intervenção familiar ou da liberdade, solidariedade familiar e função social da família- asseguram o dever de proteção aos membros da entidade familiar, cada um na sua individualidade, incluindo-se aí aquele que corre o risco de ficar em situação de abandono moral e material.

O dever de assistência imaterial configura-se como fundamental na relação familiar, determinando a prestação de cuidados e atenção. Mas, apesar de ser importante ferramenta de garantia desses direitos, o instituto da usucapião familiar tem a sua constitucionalidade questionada por aqueles que entendem que com ela, volta-se a discutir a culpa no fim das relações maritais. Diz-se que com a 
possibilidade de usucapir a quota do bem daquele que o deixa nasce no Direito uma nova forma de sanção daquele que teria dado causa ao fim do relacionamento.

Finalmente, o presente trabalho procurou demonstrar, por meio da interpretação de diversos princípios, que na verdade o instituto nada mais é do que novo elemento do direito real de usucapião, sendo que, dessa forma não há necessidade de se discutir a culpa no fim da relação conjugal, para que consequentemente haja uma sanção patrimonial do culpado, mas sim que, ao se falar equivocadamente em abandono de lar, não se deve remeter ao conceito do Direito de Família usado no século passado, e sim, reportar-se ao abandono do imóvel, enquanto patrimônio da família, que requer cuidados e conservação, e que para tanto deve haver despensas de ambos os cônjuges/ companheiros.

Não há dúvidas de que ninguém é obrigado a amar ou sentir carinho por outra pessoa, mas incumbe ao Direito ao menos oferecer proteção àqueles que não cumprem o dever de amparo mínimo necessário à dignidade da pessoa humana. Assim, apesar de se tratar de questão controversa, acredita-se que paulatinamente restará consolidado o reconhecimento da possibilidade e legitimidade da usucapião familiar, e que no futuro a questão a ser analisada em cada caso concreto ater-se-á apenas ao fato de estarem ou não preenchidos os requisitos necessários para tanto, sem se questionar culpa ou não pelo fim da sociedade conjugal.

\section{ABSTRACT}

On June 17, 2011, civil legislation was amended, introducing a new mode of use, the sequence resulting from the abandonment of the home. This article aims to critically analyze the new adverse possession and its reflexes in the area of Family Law. In fact, we think that evoking the guilt for the breakup of the relationship, invigorating the cause of homelessness, proves to be anachronistic and in countermarch to the evolution of contemporary law, in which increasingly any judicial discussion about who gave it away. cause to the role of vinyculo, leaving such issue for the intimate of individuals. Doubts arise about law enforcement, especially the interpretation of homelessness. This concept was rescued by the legislator despite the advancement of Brazilian law that allows direct divorce, in addition to the construction of jurisprudence that makes a democracy in recognizing the right to break the villous between couples. An interpretation of the new law is proposed in order to protect the right to housing, including the abandonment of an attitude of helplessness of the family, to provide protection to the situation in which a situation of vulnerability is found, allowing the regularization of the accumulation of real estate. The lawsuit must be prosecuted and tried in Family Court, because it deals with the dismissal resulting from rights and duties between ex-couples.

Keywords: Family adverse possession; homelessness and fundamental rights. 


\section{REFERÊNCIAS}

BANHARA, Ana Cláudia O. Usucapião por lar conjugal. Disponível em: http://.migalhas.com.br/usucapaiaoporabandonodelarconjuga.I. Acesso em24 de ago.2019.

BRASIL. Código Civil de 2002. Brasília: Planalto, portal.

BRASIL. Constituição da República Federativa do Brasil de 1988. Brasília:

Planalto, portal.

BRASIL, Emenda constitucional no 66, de 13 de julho de 2010. Brasília: Planalto, portal.

BRASIL, V Jornada de Direito Civil. Enunciado 499. Disponível em: http://www.cjf.jus.br/enunciados/enunciado/499. Acesso em: 19 ago.2019.

BRASIL. Lei $\mathbf{n}^{\circ}$ 10.257, de 10 de julho de 2001. Brasília: Planalto, portal.

BRASIL. Lei n¹2.424, de 16 de junho de 2011. Brasília: Planalto, portal.

CORDEIRO, Carlos José. Usucapião Constitucional Urbano:Aspectos de direito material. São Paulo: Max Limonad Disponível em:

www.passeidireito.com,br.usucapiao/familiar. Acesso em 05 de mar.2019.

DIAS, Maria Berenice. Usucapião e abandono do lar: a volta da culpa? Disponível em: https://wwibdfam.org.br/artigos/usucapiaoporabandonodelar/maraberenice.

Acesso em; 05 de mar.2019.

FARIAS, Cristiano Chaves. ROSENVALD, Nelson. Curso de Direito Civil. Direito das Famílias. Ed.7. Bahia, 2015.

FIGUEREDO, Rosio. Ususcapião conjugal: requisitos e críticas da nova modalidade de usucapião. Disponível em: www.jus.com.br/requisitosecritica.

Acesso em: 5 de ago.2019.

FREITAS, Douglas Phillips. A usucapião e Direito de Família: Comentários ao Artigo 1.240- A do Código Civil. Revista Síntese Direito de Família. V.14, n.71, 2012.

GOMES, ORLANDO. Livro Direito de Família. $9^{\circ} \mathrm{ed}$. Salvador: Forense: jusPODIVM, 1996.

MONTEIRO, Washington de Barros. Curso Direito de Família. ed.43. São Paulo: Saraiva, 2010.

PEREIRA,Caio Mário da Silva. Instituições de Direito Civil, Vol. IV. 15. ed..Rio de Janeiro: Forense, 2012. 
PEREIRA, Lafayette Rodrigues. Direito das coisas. 6. ed. São Paulo: Freitas Bastos, 1956.

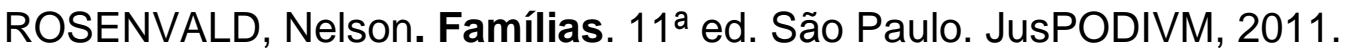

SALLES, José Carlos de Moraes. Usucapião de Bens Imóveis e Móveis. São Paulo: Revista dos Tribunais, 2006.

SALLES, José Carlos de Moraes. Usucapião de Bens Imóveis e Móveis. 7.ed. São Paulo: jusPODIVM, 2010.

VENOSA, Sílvio de Salvo. Direito Civil: direitos reais. 12. ed. São Paulo: Atlas, 2012. 